\title{
Vascular Perforation During Coil Embolization of an Intracranial Aneurysm: the Incidence, Mechanism, and Clinical Outcome
}

\author{
Chang-Woo Ryu, MD', Chul-Young Lee, MD², Jun Seok Koh², \\ Seok Keun Choi, MD², Eui Jong Kim, MD'
}

Purpose: The occurrence of a vascular perforation during an endovascular procedure is an unexpected and feared complication which can be fatal. However, the incidence, risk or the mechanism of vascular perforation which can occur in the endovascular management of aneurysms remains unclear. The purpose of the present study was to evaluate the incidence of vascular perforation during endovascular coil embolization of a cerebral aneurysm, and to reveal characteristics and clinical outcomes.

Materials and Methods: We reviewed the endovascular coil embolization procedures performed for the treatment of 459 aneurysms. Incidence and clinical, radiological and technical data of patients concerning the vascular perforation were reviewed from medical records and radiological findings.

Results: The incidence of procedure-related vascular perforation in our patient group was $0.87 \%$ (4/459). For all four occurrences, the cause of vascular perforation involved the guidewire or microcatheter. Clinical outcome was poor in 2 cases and favorable in 2 cases.

Conclusion: Although rare, the occurrence of vascular perforation during coil embolization for treatment of an aneurysm may be fatal. Therefore, careful management of the guidewire is suggested for the prevention of vascular rupture during an endovascular procedure.

Key Words : Vascular perforation; Intracranial aneurysm; Coil embolization

Endovascular treatment of intracranial aneurysms is aimed at the prevention of rupture of aneurysm with

\footnotetext{
Deapartments of ${ }^{1}$ Radiology and ${ }^{2}$ Neurosurgery, School of Medicine, Kyung Hee University, Seoul, Korea

Received October 23, 2010;

accepted after revision February 6, 2011.

Correspondence to: Jun Seok Koh, MD, Department of Neurosurgery, Kyung Hee University Hospital at Gangdong, 892 Dongnam-ro, Sangil-dong, Gangdong-gu, Seoul 134-090, Korea. Tel. 82-2-440-6145 Fax.82-2-440-7171 E-mail: gjs@khnmc.or.kr Neurointervention $2011 ; 6: 17-22$

This is an Open Access article distributed under the terms of the Creative Commons Attribution Non-Commercial License (http://creativecommons.org/licenses/by-nc/3.0) which permits unrestricted non-commercial use, distribution, and reproduction in any medium, provided the original work is properly cited.
}

the lowest possible risk of procedural complications. Perforation of an intracranial aneurysm is a well known fatal complication of an endovascular embolization which has a procedure-related rupture rate of $2-3 \%$ in the literature $(1-5)$. Many articles dealing with the risk factors and management of procedure-related ruptures have been published $(1,3,5)$. However, unlike iatrogenic rupture of aneurysms, few articles cover other causes of hemorrhagic complication. Iatrogenic vascular perforation is a complication of major concern which can result in fatal intracranial hemorrhages during endovascular neurointervention $(6-10)$. However, the incidence, risk, or mechanisms involved with vascular perforation that can occur in the endovascular management of aneurysms remains unclear. 


\section{Chang-Woo Ryu, et al.}

The authors reviewed our database of 447 consecutive patients who were treated by coil embolization for intracranial aneurysms. We present a series of patients in whom vascular perforation occurred despite achievement of an angiographically successful occlusion of the aneurysm. The purpose of the present study is to evaluate the incidence of vascular perforation during endovascular coil embolization of a cerebral aneurysm, and to reveal characteristics and clinical outcomes.

\section{MATERIALS AND METHODS}

Between May 2002 and October 2010, we reviewed endovascular coil embolization procedures performed on 459 aneurysms in 447 consecutive patients. Coiling was performed for 324 recently ruptured aneurysms and 135 unruptured aneurysms.

In accordance with a standardized protocol, coiling of aneurysms was performed with the patient under general anesthesia and systemic heparinization. All patients were subjected to full anticoagulation comprising a bolus of 3,000-5,000 IU (50 IU/ $\mathrm{kg}$ body weight) of heparin, followed by continuous infusion at a rate of $1,000-2,000 \mathrm{IU} / \mathrm{h}$. Anticoagulation aimed to hold the activated clotting time at twice the normal value (about $100 \mathrm{~s}$ ) during catheterization and coil placement. A 6$7 \mathrm{~F}$ cerebral guiding catheter was placed in the internal carotid artery or vertebral artery via using a unilateral or bilateral transfemoral approach. In wide neck aneurysms, stents or balloons were used to stabilize the placement of coils. The use of conventional coil embolization, balloon remodeling, and/or stent placement techniques were decided on a case-by-case basis. All patients treated by coil embolization underwent a CT scan immediately following the procedure and again if clinical deterioration was observed.

Parent artery rupture was diagnosed when the extravasation of contrast media from non-aneurysmal segment of artery was visualized during the procedure, intracerebral hemorrhage (ICH) or subarachnoid hemorrhage (SAH) unrelated with aneurysm location, was depicted on the immediate post-procedural CT. The case in which the instrument out of the parent artery was discovered by fluoroscopy during the procedure and the increase in SAH was depicted on post-procedural $\mathrm{CT}$, was also regarded as iatrogenic vascular perforation. Arterial blood pressure (BP) values were obtained retrospectively before and after rupture from the anesthesiology medical charts.

Clinical, radiological, and technical data concerning the vascular perforation were reviewed from medical records and radiological findings. The presence of SAH, clinical status graded by the Hunt and Hess scale, and Fisher grade before the endovascular procedure was assessed. In addition, we determined the location of the aneurysm and ruptured artery, the technique for aneurysm coiling and cause of the presumed vascular perforation, as well as the treatment after vessel rupture. Immediate post-procedural CT was evaluated for the volume of $\mathrm{ICH}$ and $\mathrm{SAH}$. We reviewed the management for procedure-induced hemorrhage, as well as morbidity and mortality at hospital discharge using the Glasgow Outcome Scale (GOS). Our institutional review board did not require approval or patient informed consent for this study.

\section{RESULTS}

Four cases of vascular perforation were found in our series of 459 consecutive aneurysms which were treated by endovascular coil embolization. The incidence of procedure-related vascular perforation per treated aneurysm in our patient group was $0.87 \%$.

The characteristics of the 4 patients $(2$ males, 2 females; mean age $52.3 \mathrm{yrs}$ ) with procedure-related vascular perforation are listed in Table 1 . Three patients underwent emergent endovascular treatment for a ruptured aneurysm, while the other patient had an unruptured aneurysm. All of the three patients with a ruptured aneurysm presented with a good clinical grade

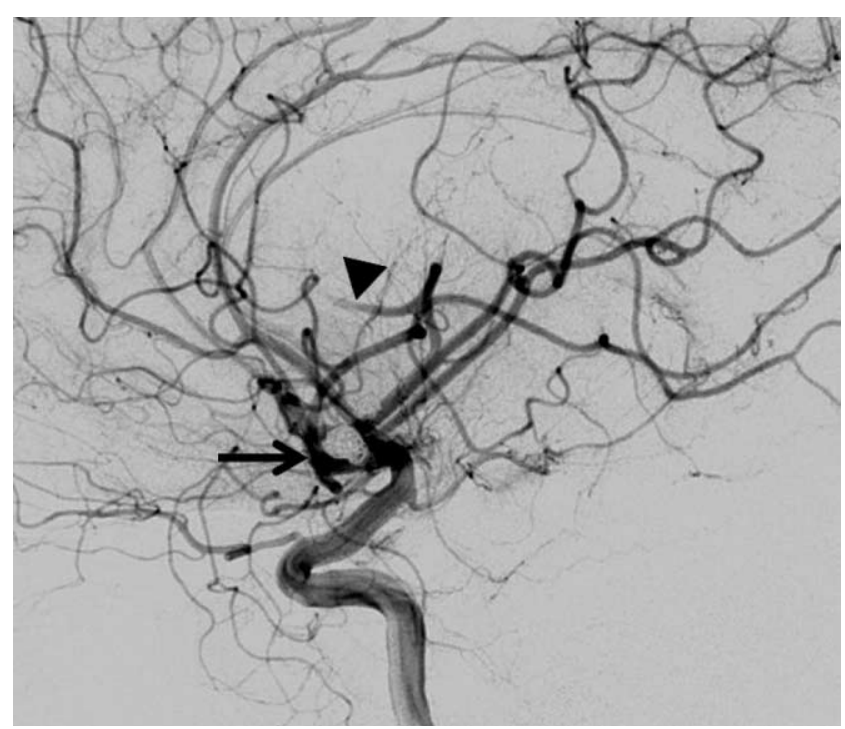

Fig. 1. A 44-year-old man with diffuse subarachnoid hemorrhage and rupture of anterior communicating artery aneurysm (Case No. 4). After coil embolization of aneurysm, left carotid angiogram reveals coil mesh within aneurysm (arrow) and embolic occlusion of parietal branch of left middle cerebral artery (arrowhead). 
(Hunt \& Hess scale, 1-3) and diffuse SAH (Fisher grade II-III) on preprocedural CT. The location of the aneurysms was in the right ventral paraclinoid internal carotid artery (ICA), distal posterior cerebral artery (PCA), distal anterior cerebral artery (ACA), and anterior communicating artery (ACoA). The three cases were treated by conventional coil embolization, while the other case underwent a stent placement technique.

As presumed by our review of the angiography and immediate post-procedural CT, rupture of the artery occurred in two distal middle cerebral arteries (MCA), and one distal PCA, and one distal ACA. The most common cause was a guidewire and/or microcatheter in whole four cases. The case of ICA aneurysm treated with stent placement techniques were the distal MCA rupture cases that resulted from the guidewire used for guiding the stent. In addition, post-procedural CT of this case showed ICH in right frontal lobe. The vessel rupture of two cases with aneurysms of distal ACA and
PCA and caused by the guiding of a microcatheter during aneurysm selection. The one distal MCA rupture by the guidewire and microcatheter happened during thrombolysis for the treatment of the thromboembolic complication involving distal MCA (Fig. 1). The case with distal PCA rupture showed extravasation of contrast media, and increased BP. After recognition of rebleeding, heparinization was immediately reversed with intravenously administered protamine sulfate $(40-50 \mathrm{mg})$, and blood pressure was decreased. In this case, extravasation to the ventricle was spontaneously stopped. The other three cases did not present the increase of blood pressure or extravasation of the contrast media during the procedure. Because operators were not aware of vascular perforations, any additional management could be processed for vascular perforation until the finish of the endovascular procedure.

The major findings of post-procedural $\mathrm{CT}$ in 3 cases (patients with PCoA, ACoA, and ACA aneurysms)

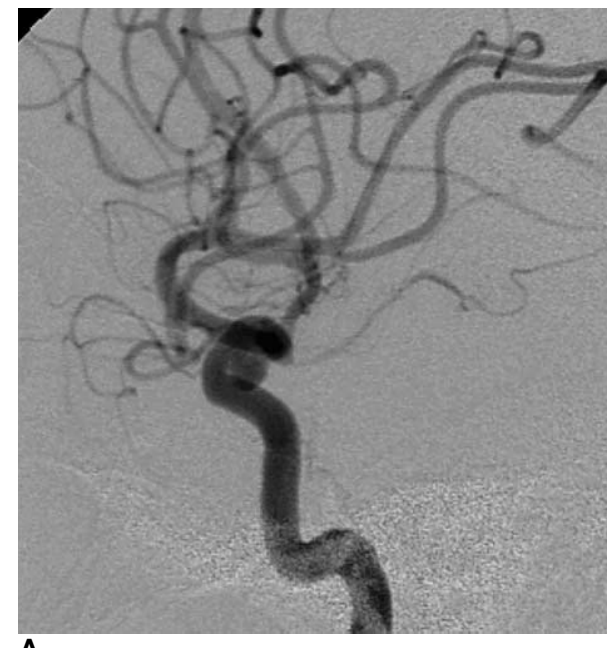

A
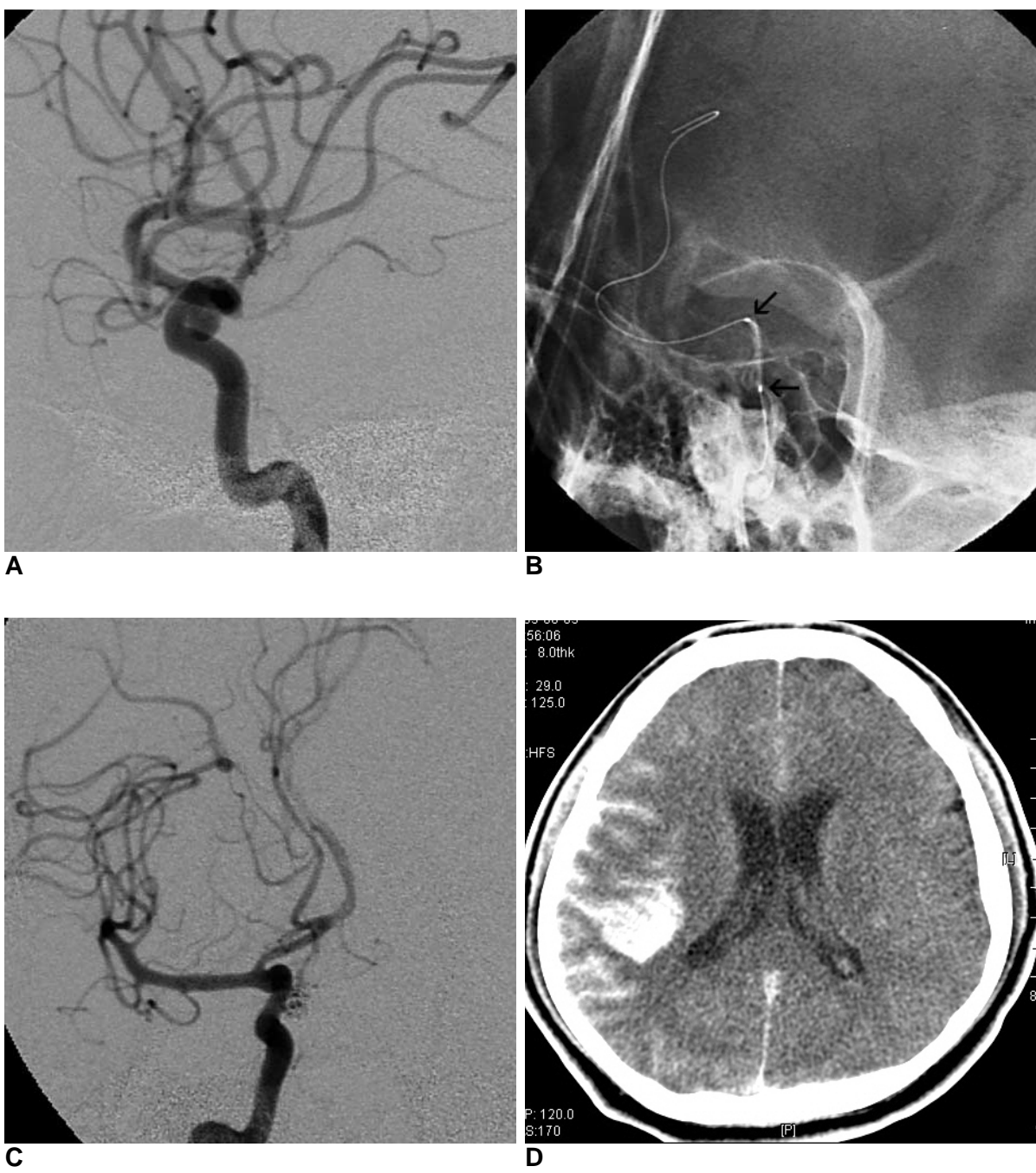

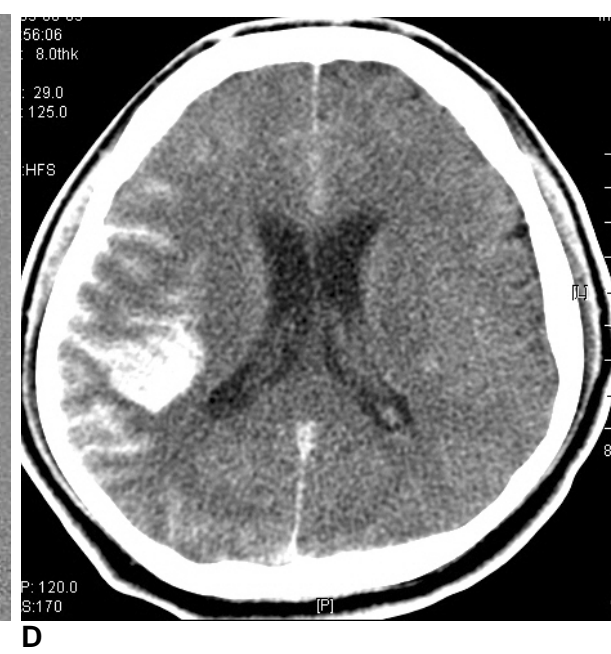

Fig. 2. A 48-year-old man presents with sudden onset of severe headache and drowsy mentality (Case No.1).

A. Right carotid angiogram reveals a multilobulated ventral paraclinoid aneurysm.

B. The guidewire is within the distal parietal branch of right middle cerebral artery. This stiff guidewire has been used to support the navigation of a balloon-expandable sent (arrows) toward a wide-neck aneurysm (At that time, the self-expandable stent was not launched in Korea).

C. At the end of the procedure, the final angiogram shows successful occlusion of the aneurysm without coil protrusion into the parent artery. Any extravasation of contrast was not identified on working angle of the right carotid angiogram.

D. Immediate post-procedural CT scan shows intracerebral hemorrhage in the right temporal lobe. 


\section{Chang-Woo Ryu, et al.}

include a parenchymal hematoma. Hematomas were managed by a craniotomy with evacuation of the hematoma. One case with a distal PCA aneurysm showed internal ventricular hemorrhage (IVH) and ICH on post-procedural $\mathrm{CT}$, and this case was treated conservatively. The GOS at hospital discharge was 1 and 2 in 2 cases, and 4 in the other 2 cases.

\section{ILLUSTRATIVE CASE}

A 48-year-old man presented with a sudden onset of a severe headache and a drowsy mentality (Hunt \& Hess scale II). CT revealed diffuse SAH (Fisher grade II) in the basal and bilateral sylvian cisterns. A right internal carotid angiogram demonstrated a lobulated, saccular aneurysm with a wide aneurysm neck on right paraclinoid ICA (Fig. 2A). To protect the protrusion of coil loops into the parent artery, we decided to use the stent-assisted technique.

Under general anesthesia, a $6 \mathrm{~F}$ guiding catheter was placed at the right ICA. To support the advance of the stent, the tip of the exchange guidewire $(260 \mathrm{~cm})$ was positioned at the M3 level of the posterior parietal branch of the right MCA using the catheter exchange technique (Fig. 2B). An over-the-wire balloon expandable stent S670 (Medtronic USA Inc., Minneapolis, Minnesota, USA) was then navigated to cover the aneurysm neck. Then, the balloon expandable stent was successfully deployed at the segment spanning from the cavernous ICA to the ICA terminum. During the procedure, extravasation of contrast media or the paradoxical elevation of blood pressure did not occur. The aneurysm was selected with a microcatheter through the strut of the stent, and 6 detachable coils were delivered into the aneurysm lumen. A 4,000 unit bolus injection of heparin was administered, followed by the first coil delivery within the aneurysm. After intra-aneurysmal positioning of detachable coils, the aneurysm was nearly completely occluded (Fig. 2C).

An immediate post-procedural CT indicated that a parenchymal hematoma mixed with contrast media was seen in the right temporal lobe and the extravasation of contrast media in subarachnoid space along right cerebral convexity (Fig. 2D). Protamine sulfate was administrated to reserve the heparin and subsequently, an emergent craniectomy with evacuation of hematoma was performed. Two days later, an oral antiplatelet medication was administered for 6 weeks after performing the procedure. At discharge, the patient showed an alert mental status with mild weakness of the left side. A follow-up angiography revealed the occlusion of aneurysm and good patency of the lumen of the right ICA.

\section{DISCUSSION}

Vascular perforation during an endovascular procedure is an unexpected complication of concern, because it can lead to serious results. Iatrogenic hemorrhage resulting from vascular perforation can abruptly increase the intracranial pressure, resulting in death. In our series, the rate of vascular perforation during endovascular management of an aneurysm was $0.78 \%$. The reported percentage of vascular perforations that were complicated with intracranial endovascular procedures varies among studies. The rate of

Table 1. Clinical and Radiological Characteristics of Patients with Procedure-related Vascular Perforation

\begin{tabular}{|c|c|c|c|c|c|c|c|c|c|c|c|c|}
\hline $\begin{array}{l}\text { Case } \\
\text { No. }\end{array}$ & $\begin{array}{l}\text { Age/ } \\
\text { Sex }\end{array}$ & $\begin{array}{c}\mathrm{SAH} \\
\text { (Fisher } \\
\text { Grade) }\end{array}$ & $\begin{array}{l}\mathrm{H}-\mathrm{H} \\
\text { Scale }\end{array}$ & $\begin{array}{l}\text { Aneurysm } \\
\text { Location }\end{array}$ & $\begin{array}{c}\text { Intervention } \\
\text { Technique }\end{array}$ & $\begin{array}{c}\text { Extravasation } \\
\text { on } \\
\text { Angiogram }\end{array}$ & $\begin{array}{c}\text { Elevation } \\
\text { of } \\
\text { BP }\end{array}$ & $\begin{array}{l}\text { Post- } \\
\text { CT }\end{array}$ & $\begin{array}{l}\text { Perforated } \\
\text { Artery }\end{array}$ & $\begin{array}{c}\text { Cause } \\
\text { of } \\
\text { Rupture }\end{array}$ & Management & GOS \\
\hline 1 & $48 / \mathrm{M}$ & 3 & 2 & $\begin{array}{l}\text { Paraclinoid } \\
\text { ICA (R) }\end{array}$ & $\begin{array}{l}\text { Stent \& } \\
\text { Coils }\end{array}$ & No & No & $\mathrm{ICH}$ & Distal MCA & Wire & $\begin{array}{l}\text { Craniotomy } \\
\text { \& Evacuation }\end{array}$ & 4 \\
\hline 2 & $48 / F$ & 3 & 3 & Distal PCA (L) & Coils & Yes & Yes & $\mathrm{IVH}, \mathrm{ICH}$ & Distal PCA & Wire & Conservation & 2 \\
\hline 3 & ${ }^{*} 69 / F$ & - & - & Distal ACA (R) & Coils & No & No & $\mathrm{ICH}$ & Distal ACA & $\begin{array}{c}\text { Wire } \\
\text { \& Catheter }\end{array}$ & $\begin{array}{c}\text { Craniotomy \& } \\
\text { Evacuation }\end{array}$ & 1 \\
\hline 4 & $44 / \mathrm{M}$ & 2 & 3 & $\mathrm{ACoA}$ & Coils & No & No & $\mathrm{ICH}$ & ${ }^{\dagger}$ Distal MCA & $\begin{array}{c}\text { Wire } \\
\text { \& Catheter }\end{array}$ & $\begin{array}{c}\text { Craniotomy \& } \\
\text { Evacuation }\end{array}$ & 4 \\
\hline
\end{tabular}

Abbreviation: SAH, subarachnoid hemorrhage; H-H Scale, Hunt-Hess scale; BP, blood pressure; Post-CT, post-procedural CT; GOS, Glascow Outcome Scale; ICA, internal carotid artery; R, right; ICH, intracerebral hemorrhage; MCA, middle cerebral artery; PCA, posterior cerebral artery; L, left; IVH, intraventricular hemorrhage; ACA, anterior cerebral artery; ACoA, anterior communicating artery

\footnotetext{
${ }^{*}$ Case of unruptured aneurysm

${ }^{\dagger}$ Perforation of distal MCA by the guidewire and microcatheter during thrombolysis for the embolic occlusion of MCA
} 
vascular perforation related with neurointerventions within the largest series (1,200 procedures) was presented by Halbach et al. (6). They stated that the rate of vascular perforation which was a direct result of these procedures was $1.1 \%$. However, they included the whole kind of neurointerventional procedure (cerebral arteriovenous malformations, tumors, carotid cavernous fistulas, aneurysms, spinal arteriovenous malformations, and so on) in the population. Several reports about mechanical thrombectomy for an acute stroke showed relative high incidence of vascular perforation $(4-9 \%)(9-10)$. In our results, all cases of vascular perforation were related to the guidewire. However, the stent itself or balloon for the remodeling of aneurismal neck, in rare cases, could be the cause of the vascular perforation. Coronary arterial perforation is also a particularly feared complication of percutaneous coronary intervention. Coronary perforations complicated $0.5-1 \%$ of all procedures and was less commonly observed in injuries related with the guidewire $(11-12)$.

To try to reduce the rate of vascular perforation, it is important to determine which factors affect the rate of occurrence. In the present study, the guidewires were advanced too far distal to select aneurysms located in the distal arteries, navigate to the stent, or manage the thrombus that migrated distally. Then, the guidewire would perforate the smaller distal vessels, which had thinner walls, rather than the proximal arteries. The more distally guidewires navigate, the more it can pass the tortuous curve of intracranial artery. Therefore, the guidewire that locates to a distal artery can keep the strong physical tension and is difficult to control. In particular, the exchange catheter technique with long exchange wire can have risk of a "forward jump". To reduce the risk of iatrogenic vascular perforation, the procedure that selects a distal artery with a guidewire should be performed more carefully.

Vascular perforation by a guidewire may result in self-sealing, particularly if it is a puncture rather than a tear. However, anticoagulation during the procedure may disturb the self-sealing. Unlike the rupture of the aneurysm itself, most of our cases (3/4) consist of the vascular perforation did not show the leakage contrast media on angiography, and not present the increase of blood pressure. Although the vessel rupture induces a treacherous slow leakage which may lead to a progressively life-threatening large bleeding, the vessel rupture during procedure may be difficult to identify. Perforation of the small distal artery may be only seen as the stagnation of the contrast media or the focal vascular spasm without extravasation in contrast media $(11,13,14)$. Therefore, when guidewire has been placed within the distal branch of the cerebral artery during procedure, vascular injury should be ruled out through an angiography with large field of view.

Our results presented the high rate of mortality and morbidity of vascular perforation during the coil embolization of an aneurysm. Therefore, when vascular perforation is detected the during procedure, this may be fetal, and the treatment should be rapid. After identifying of the vascular perforation in endovascular procedure, treatment of the vascular perforations is started with the immediate reversal of anticoagulants. Then, the operator should consider permanent occlusion of the perforation site. Closure of the perforation can be achieved with coils, liquid adhesives, or a tamponade with balloons (6).

In conclusion, although rare occurrence of vascular perforation during coil embolization of the aneurysm, the clinical outcome may be fetal. Then, the decision to treat should be rapid. The vascular perforation by guidewire may be difficult to detect and this results in improper treatment. Therefore, the prevention of the vascular rupture should be considered during the endovascular procedure, especially, guidewire navigation to distal arteries.

\section{References}

1. Brisman JL, Niimi Y, Song JK, Berenstein A. Aneurysmal rupture during coiling: low incidence and good outcomes at a single large volume center. Neurosurgery 2005;57:1103-1109

2. Grunwald IQ, Papanagiotou P, Politi M, Struffert T, Roth C, Reith W. Endovascular treatment of unruptured intracranial aneurysms: occurrence of thromboembolic events. Neurosurgery 2006;58: 612-618

3. Pierot L, Cognard C, Anxionnat R, Ricolfi F. Ruptured intracranial aneurysms: factors affecting the rate and outcome of endovascular treatment complications in a series of 782 patients (CLARITY study). Radiology 2010;256:916-923

4. Ricolfi F, Le Guerinel C, Blustajn J, Combes C, Brugieres P, Melon E, et al. Rupture during treatment of recently ruptured aneurysms with Guglielmi electrodetachable coils. AJNR Am J Neuroradiol 1998;19:1653-1658

5. Sluzewski M, Bosch JA, van Rooij WJ, Nijssen PC, Wijnalda D. Rupture of intracranial aneurysms during treatment with Guglielmi detachable coils: incidence, outcome, and risk factors. $J$ Neurosurg 2001;94:238-240

6. Halbach VV, Higashida RT, Dowd CF, Barnwell SL, Hieshima GB. Management of vascular perforations that occur during neurointerventional procedures. AJNR Am J Neuroradiol 1991;12: 319-327

7. Terada T, Okuno T, Hayashi S, Nakamura Y, Nakai K, Itakura T, et al. A case of vessel perforation during interventional neuroradiological procedure. Operative findings of the perforated vessel. 


\section{Chang-Woo Ryu, et al.}

Surg Neurol 1993;40:241-244

8. Wada H, Piotin M, Boissonnet H, Spelle L, Mounayer C, Moret J. Carotid rupture during stent-assisted aneurysm treatment. AJNR Am J Neuroradiol 2004;25:827-829

9. Flint AC, Duckwiler GR, Budzik RF, Liebeskind DS, Smith WS. Mechanical thrombectomy of intracranial internal carotid occlusion: pooled results of the MERCI and Multi MERCI Part I trials. Stroke 2007;38:1274-1280

10. IMS Study Investigators. Combined intravenous and intra-arterial recanalization for acute ischemic stroke: the Interventional Management of Stroke Study. Stroke 2004;35:904-911

11. Dippel EJ, Kereiakes DJ, Tramuta DA, Broderick TM, Shimshak TM, Roth EM, et al. Coronary perforation during percutaneous coronary intervention in the era of abciximab platelet glycoprotein
IIb/IIIa blockade: an algorithm for percutaneous management. Catheter Cardiovasc Interv 2001;52:279-286

12. Javaid A, Buch AN, Satler LF, Kent KM, Suddath WO, Lindsay $\mathrm{J}$, Jr., et al. Management and outcomes of coronary artery perforation during percutaneous coronary intervention. Am J Cardiol 2006;98:911-914

13. Axelrod DJ, Freeman H, Pukin L, Guller J, Mitty HA. Guide wire perforation leading to fatal perirenal hemorrhage from transcortical collaterals after renal artery stent placement. J Vasc Interv Radiol 2004;15:985-987

14. Gorich J, Rilinger N, Mickley V, Wikstrom M, Pamler R, Brambs HJ. Management of iatrogenic hemorrhage after mechanical vascular recanalization. Aktuelle Radiol 1996;6:28-31 